\title{
Effect of axial compression on ductility design of RC walls
}

1 Y. P. Yuen BEng, PhD

Assistant Professor, Department of Civil Engineering, Bursa Orhangazi Üniversitesi, Bursa, Turkey
2 J. S. Kuang PhD, CEng, FICE, FIStructE, FHKIE

Professor, Department of Civil and Environmental Engineering, The Hong Kong University of Science and Technology, Hong Kong
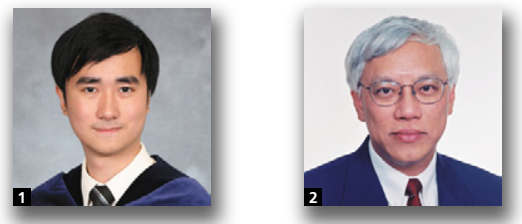

Reinforced concrete (RC) structural walls can render excellent lateral stability and ductility to medium to high-rise buildings, but are generally subjected to very high axial compression loading, which can reduce the inherent ductility. A comprehensive statistical analysis with $\mathbf{4 7 4}$ sets of experimental data was conducted to evaluate and quantify the effect of the axial compression ratio (ACR) on the structural performance of RC structural walls. The stipulated limits on the ACR and the methods of evaluation used in various design codes were compared. Provisions on the limits of the ACR stipulated in various design codes were compared, and the expected attainable ductility factors for RC walls designed to different codes were evaluated. It was found that the provisions on ACR limits in Eurocode 8 generally satisfy the target ductility level but a distinction needs to be made between non-squat and squat walls due to their different structural behaviours.

\section{Notation}

A cross-sectional area of concrete section

$A_{\mathrm{c}} \quad$ gross area of the concrete section

$A_{\mathrm{g}} \quad$ cross-sectional area of a wall segment

$A_{\mathrm{w}} \quad$ web area of wall

$c \quad$ natural axis depth

E seismic action

$E_{\mathrm{ci}} \quad$ Young's modulus of unconfined concrete

$E_{\mathrm{cl}} \quad$ secant modulus from the origin to the peak compressive stress

$E_{y} \quad$ Young's modulus of steel reinforcement

$f_{\mathrm{c}} \quad$ uniaxial compressive strengths of unconfined concrete

$f_{\mathrm{c}}^{\prime} \quad$ design axial compressive strength of concrete under uniaxial compression at 28 days

$f_{\mathrm{cc}} \quad$ uniaxial compressive strengths of confined concrete

$f_{\text {cd }} \quad$ design cylinder strength (with a safety factor of 1.5) of concrete under uniaxial compression at 28 days characteristic axial strength of concrete

$f_{\text {cu }} \quad$ characteristic cube strength of concrete under uniaxial compression at 28 days

$f_{1} \quad$ effective confining stress provided by the confining reinforcement

$f_{\mathrm{s}} \quad$ stress in reinforcement steel

$f_{\mathrm{si}} \quad$ stress in the $i$ th reinforcement steel

$f_{\mathrm{y}} \quad$ uniaxial yield strength of steel

$G_{\mathrm{k}} \quad$ total permanent or dead load

$H$

$k$

$L$

$l_{\mathrm{p}}$

$N_{\text {ED,EC }}$

$N_{\mathrm{W}, \mathrm{C}}$

$N_{\mathrm{W}, \mathrm{HK}}$

$Q_{\mathrm{k}}$

$Q_{k i}$ height of wall

$E_{\mathrm{ci}} / E_{\mathrm{il}}$

length of wall

length of plastic hinge

web length of wall

bending moment

axial compression

design axial force from the analysis for seismic design

factored axial force for the wall design axial force

total live load

variable action

combination coefficient for variable action $i$ due to the representative gravity load (Equation 12)

thickness of wall

peak shear force

distance measured from the wall edge

ground displacement

strain penetration effect

displacement at the top of the building relative to

the ground

ultimate displacement

yield displacement

vertical aspect ratio

ultimate top displacement

yield top displacement 


\begin{tabular}{|c|c|}
\hline$\varepsilon_{\mathrm{c}}$ & concrete compressive strain \\
\hline$\varepsilon_{\mathrm{cc}}$ & $\begin{array}{l}\text { strain at the peak compressive stress of confined } \\
\text { concrete }\end{array}$ \\
\hline$\varepsilon_{\mathrm{c} 1}$ & $\begin{array}{l}\text { strain at the peak compressive stress of unconfined } \\
\text { concrete }\end{array}$ \\
\hline$\varepsilon_{\mathrm{cu}}$ & ultimate crushing strain of concrete \\
\hline $\mathrm{m}$ & rupture strain of steel reinforcement \\
\hline$\varepsilon_{\mathrm{t}}$ & strain in the extreme tensile fiber \\
\hline$\varepsilon_{\mathrm{y}}$ & steel yielding strain \\
\hline$\eta$ & axial compression ratio \\
\hline$\mu_{\varphi}$ & curvature ductility factor \\
\hline$\mu_{\Delta}$ & displacement ductility factor \\
\hline$v_{\mathrm{n}}$ & normalised shear strength \\
\hline$\rho_{\mathrm{v}}$ & volumetric ratio of the confinement reinforcement \\
\hline$\sigma_{\mathrm{c}}$ & compressive stress \\
\hline$\varphi_{\mathrm{p}}$ & plastic sectional curvature \\
\hline$\varphi_{\mathrm{u}}$ & ultimate sectional curvature \\
\hline$\varphi_{\mathrm{y}}$ & yield sectional curvature \\
\hline$\psi_{E, i}$ & combination coefficient (Equation 10) \\
\hline & nechanical confining reinforcement ratio \\
\hline
\end{tabular}

\section{Introduction}

Catastrophic collapse of reinforced concrete (RC) buildings clearly necessitates the dragging down of vertical structural members; for instance, the failure of structural walls can lead to potential overall structural instability. In view of this, the capacity protection of walls and primary columns through special design and detailing is one of the most critical issues in seismic design (fib, 2012; Kappos and Penelis, 1996; Park, 1986; Paulay and Priestley, 1992). It has been demonstrated in many disastrous earthquakes (Fintel, 1992) that well-designed structural walls can provide excellent lateral stability and drift ductility to medium- to high-rise RC buildings under seismic action.

To achieve the goal of capacity design, the enhancement and preservation of sufficient ductility of RC structural walls are achieved through confinement details, the requirements of which are significantly influenced by the level of the axial force induced on the walls. The effect of axial force on the seismic behaviour of RC walls is actually known from experience, but the force and behaviour are correlated in many aspects. Although the curvature ductility of RC sections can be readily evaluated at different levels of axial force, the relationships between the axial force and the buckling tendency of longitudinal reinforcing bars and the cyclic fatigue of the members are quite complicated, especially under seismic loading (Paulay and Priestley, 1992). However, the axial force can also have some positive effect on the structural behaviour, such as supressing shear sliding and premature anchorage failure (Kappos and Penelis, 1996). Hence the actual seismic responses of RC walls under a significant axial force can be complicated, given that interactions between different axial force effects and failure mechanisms further complicate the situation. Nonetheless, both research studies ( $\mathrm{Su}$ and Wong, 2007; Zhang and Wang, 2000) and disastrous earthquakes (Adebar, 2013; Wallace et al., 2012) have repeatedly revealed that the adverse effect of axial compression on $\mathrm{RC}$ walls generally overwhelms the benefits introduced.

The Chile earthquake in 2010 is a good example, showing the effect of high axial forces on the seismic performance of RC walls. Post-earthquake field investigations indicated that thin walls, with thickness ranging from 150 to $200 \mathrm{~mm}$ and designed to the modern standards, in newly built high-rise buildings were subjected to higher axial compression than thicker walls in the old buildings, and surprisingly suffered more severe damage during the earthquake (EERI, 2010). This shows that the use of reinforcement detailing cannot guarantee desirable seismic performance of walls when they are subjected to high axial compression. Modern complex structures and super-high-rise skyscrapers, both in Chile and in other parts of the developed world, are also often characterised by high compression forces in very slender members, as a consequence of architectural designs that maximise clear floor heights and usable floor areas. Recent studies (Su and Wong, 2006; Wallace et al., 2012) have indicated that structural walls in modern high-rise buildings would sustain an axial compression ratio (ACR) of 0.4 or above, which is much higher than the typical range of $0-0 \cdot 2$.

To avert undesirable brittle failures of RC members, on the basis of the work by Chronopoulos and Vinzileou (1995), Eurocode 8 (BSI, 2004) stipulates the limits for the normalised axial force, also known as the 'axial force ratio', for RC members in various ductility classes, despite the largely scattered results (Tassios, 1996). Chinese (MCPRC, 2012) and Hong Kong (HKSAR-BD, 2013) design codes impose similar requirements to Eurocode 8. However, not all modern design codes, for instance, New Zealand, American and Canadian codes (ACI, 2011; SNZ, 2006), use the same measure to limit the ACR in the design of RC structures. There is apparently no consensus among the different engineering and research communities on whether limiting the ACR is crucial to the ductile or capacity design of RC walls to withstand seismic loading. In view of this, in the present study the effect of the ACR on seismic performance of RC structural walls was revisited and a statistical analysis undertaken in order to compare and discuss the rationale of the relevant provisions in various design codes. The aim was to shed light on the justification of the use of ACR in the design of RC walls to determine a suitable limit to control the seismic performance of RC structures.

\section{Failure modes of walls}

\subsection{Slender walls}

Failure modes of walls are governed by the slenderness and axial compression. It is well recognised that the failure modes and mechanisms of slender and squat walls are very different. Slender walls often fail in the flexural mode, with prominent horizontal cracks developing in plastic hinges, usually at the base. Under low axial compression, the collapse of slender walls is due either to low-cycle fatigue fracture of reinforcement in the 
tensile zone, or to concrete crushing followed by buckling of vertical reinforcement in the compression zone. For slender walls subjected to high axial compression, compression failure (Figure 1(a)) or lateral buckling is likely to occur after sufficient horizontal cracks have developed during the cyclic loading.

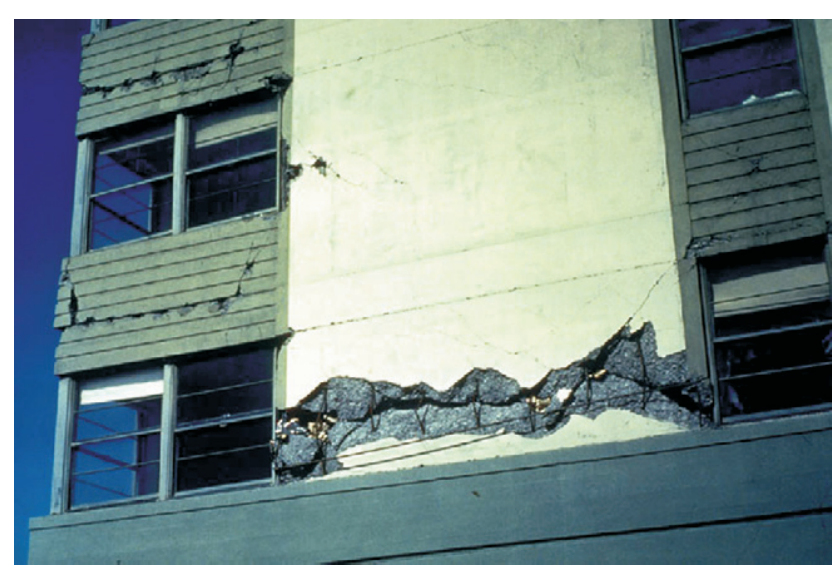

(a)

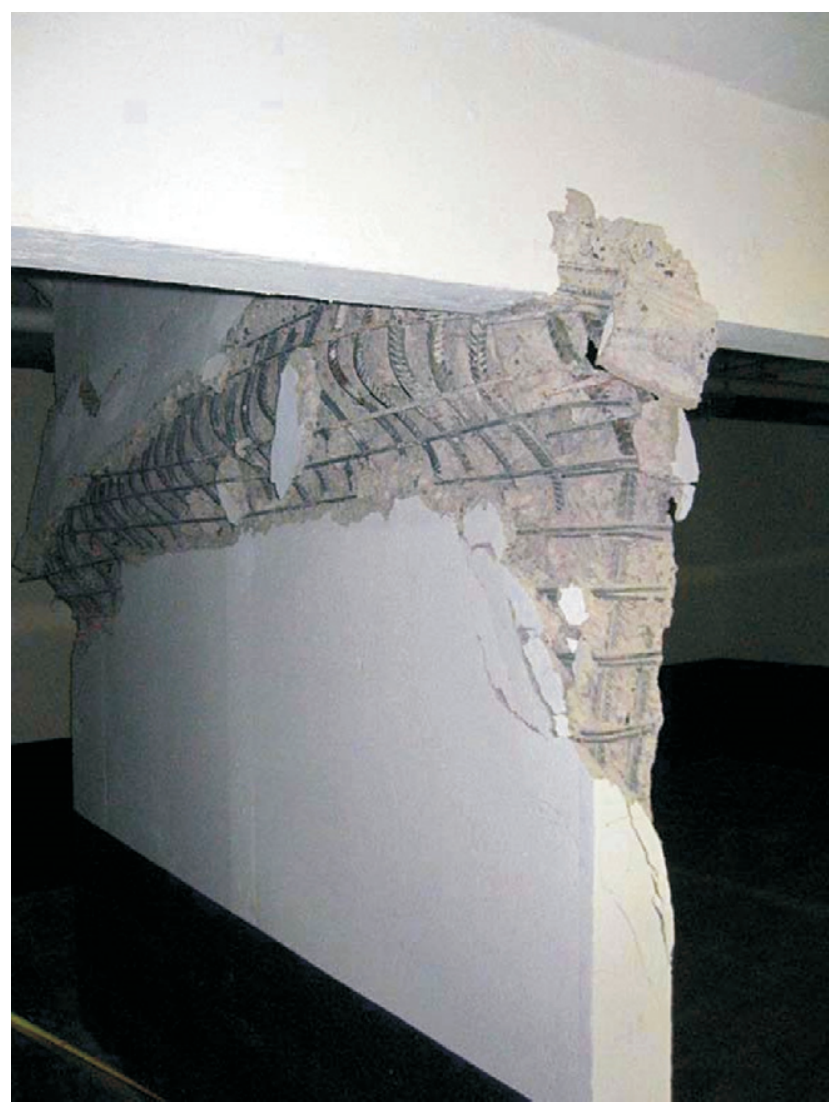

(b)

Figure 1. Failure modes of a shear wall: (a) compression failure of a wall in the 1964 Alaska earthquake; (b) lateral buckling of a wall during the 2010 Chile earthquake; (c) shear failure of a wall during the 1999 Izmit earthquake. (Courtesy of Vitelmo V. Bertero

\subsection{Squat walls}

For squat walls, little or no flexural yielding will occur before shear failure, resulting in non-ductile structural behaviour. Shear failure of squat walls can be in the form of diagonal tension, diagonal compression or sliding shear. Diagonal tension failure, where diagonal shear cracks develop across the entire length of the wall, is likely to occur in walls having little horizontal reinforcement and low axial compression (Figure 1(c)). On the other hand, diagonal compression failure or web crushing, where localised concrete crushing occurs at one end of the diagonal strut, often takes place in walls subjected to high axial compression. Sliding shear failure is also likely to occur in walls having low axial compression and aspect ratio. Horizontal sliding planes are created when the cracks from one side intersect those from the other side during reversed cyclic loading.



for (a), M. Francisco for (b) and Andrew S. Whittaker for (c); acquired from the NISEE e-Library, EERC, University of California, Berkeley, CA, USA) 


\section{Axial compression ratio}

\subsection{Definition of ACR}

To parametrise the axial compression effect on the structural performance of RC walls, in the literature the axial compression is generally normalised using the concrete uniaxial compressive strength multiplied by the sectional area of the concrete member. That is, the ACR $\eta$ is defined as

$$
\text { 1. } \eta=\frac{N}{f_{c} A}
$$

where $N$ is the axial compression, $f_{\mathrm{c}}$ is uniaxial compressive strength of concrete, and $A$ is the cross-sectional area of the concrete section. Besides the confinement detailing, aspect ratios, lap and splices etc., the ACR is a very important factor in evaluating the expected ductility and fragility of RC walls during earthquakes. However, it should not be confused with limit-state design concepts, as the ACR alone cannot represent or be used to assess the actual seismic performance of RC structural walls.

\subsection{Axial compression effect on ductility}

Axial force plays a crucial role in governing the drift ductility of RC walls. An apparent and instant effect at higher axial compression is a reduction in the curvature ductility of the walls (Paulay and Priestley, 1992; Priestley et al., 2007). The relationship between the curvature ductility $\phi_{\mathrm{u}}$ and the axial compression is illustrated in Figure 2. The curvature ductility is directly inversely proportional to the natural axis depth $c$, which in turn is a monotonically increasing function of the axial compression. Hence, the curvature ductility, as well as the total drifts ductility of the wall of height $H$ (Figure 3) decreases with increasing axial compression.

If the strain penetration effect $\Delta_{\mathrm{sp}}$ is deemed to be negligible, and assuming a plastic hinge length of $l_{\mathrm{p}} \approx 0 \cdot 5 l_{\mathrm{w}}$, the normalised drift capacity and ductility of flexurally controlled wall segments can then be estimated as

2. $\frac{\Delta_{u}}{H}=\varepsilon_{\mathrm{y}}\left(\frac{\alpha_{\mathrm{v}}}{1 \cdot 5}-1\right)+\frac{\varepsilon_{\mathrm{cu}} l_{\mathrm{w}}}{2 \cdot 0 c}$

where $\alpha_{\mathrm{V}}$ is the vertical aspect ratio $H / l_{\mathrm{w}}$, and $\mu_{\Delta}$ is the displacement ductility factor. Equation 3 further indicates that the aspect ratio $\alpha_{\mathrm{V}}$, concrete crushing strain $\varepsilon_{\mathrm{cu}}$ and steel yielding strain $\varepsilon_{\mathrm{y}}$ are also effective parameters for representing the drift ductility of a wall segment, and the natural axis depth $c$ is an influential parameter. The accuracy of Equations 2 and 3 was tested against experimental data from the SLDRCE Database (Zhou and Lu, 2010). The predicted results for the drift ductility and ultimate drift ratio are plotted against the experimental data in Figure 4. Linear regressions of the predicted results

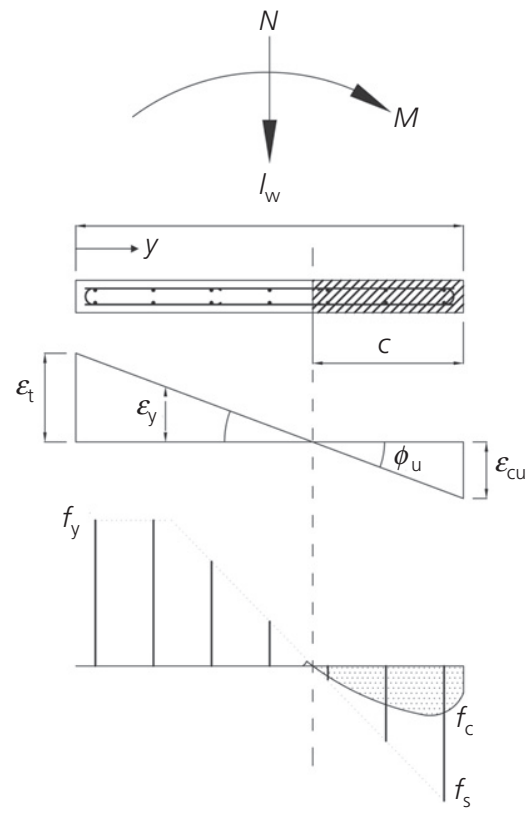

Axial force balance

$N=\sum_{i} f_{s i}+\int_{c}^{I_{c}} f_{c} \mathrm{~d} y$

Movement balance

$M=\sum_{i} f_{s i} y_{i}+\int_{c}^{I_{w}} f_{c} y d y$

Ultimate and yield curvatures of walls (Priesley et al., 2007)

$\phi_{u}=\frac{\varepsilon_{\mathrm{cu}}}{\mathrm{C}} \quad \phi_{u}=2.00 \frac{\varepsilon_{\mathrm{y}}}{I_{\mathrm{w}}}$

Curvature ductility of walls

$\mu_{\phi} \approx \frac{\varepsilon_{c u} l_{w}}{2 \cdot 00 \varepsilon_{\mathrm{y}} \mathrm{C}}$

Figure 2. Relationship between the curvature ductility and the internal forces in the walls 


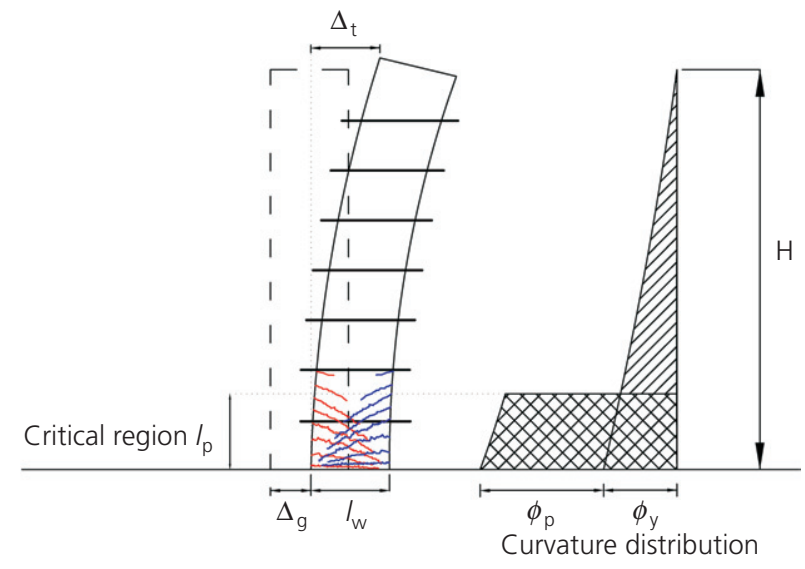

Figure 3. Drift and plastic hinge region in cantilever RC walls under seismic action

against the experimental data, also plotted in Figure 4, have slopes close to unity, which indicates that the drift ductility and ultimate drift ratio of RC walls can be closely predicted using Equations 2 and 3.

As an illustrative example to show the effect of the ACR, confinement and aspect ratios on ductility, a group of four RC walls having the same cross-section $(1700 \gamma 200 \mathrm{~mm})$ but different aspect ratios (2, 4, 6 and 8$)$ was considered. The walls were longitudinally reinforced with two layers of R10 bars spaced at $200 \mathrm{~mm}$ on the centre, as shown in Figure 2 together with various boundary elements details. The concrete cover was $25 \mathrm{~mm}$. The material properties of the unconfined concrete were $f_{\mathrm{c}}=38 \mathrm{MPa}, E_{\mathrm{ci}}=33.6 \mathrm{GPa}, \varepsilon_{\mathrm{cl}}=0.00238$ and $\varepsilon_{\mathrm{cu}}=$ $0 \cdot 0035$, and the material properties of the reinforcement were $f_{\mathrm{y}}=500 \mathrm{MPa}, E_{\mathrm{y}}=200 \mathrm{GPa}$ and $\varepsilon_{\mathrm{sm}}=0 \cdot 15$. The concrete stress-strain curve is defined based on the fib Model Code 2010 ( $f$ ib , 2012) as follows

4. $\frac{\sigma_{c}}{f_{c}}=-\left(\frac{k \eta-\eta^{2}}{1+(k-2) \eta}\right)$

where $\sigma_{\mathrm{c}}$ is the compressive stress, $\eta=\varepsilon_{\mathrm{c}} / \varepsilon_{\mathrm{cl}}$ and $k=E_{\mathrm{ci}} / E_{\mathrm{cl}}$. Based on Mander et al. (1988) and Park and Paulay (1975), the confined concrete properties in the boundary elements at different values of the mechanical confining reinforcement ratio $\left(\omega_{\mathrm{v}}=\rho_{\mathrm{v}} f_{\mathrm{y}} / f_{\mathrm{c}}\right)$ are calculated as

5. $f_{\mathrm{cc}}=f_{\mathrm{c}}\left(-1 \cdot 254+2 \cdot 254 \sqrt{1+\frac{7 \cdot 94 f_{1}}{f_{\mathrm{c}}}}-\frac{2 f_{1}}{f_{\mathrm{c}}}\right)$

6. $\varepsilon_{\mathrm{cc}}=\varepsilon_{\mathrm{c} 1}\left[1+5\left(f_{\mathrm{cc}} / f_{\mathrm{c}}-1\right)\right]$

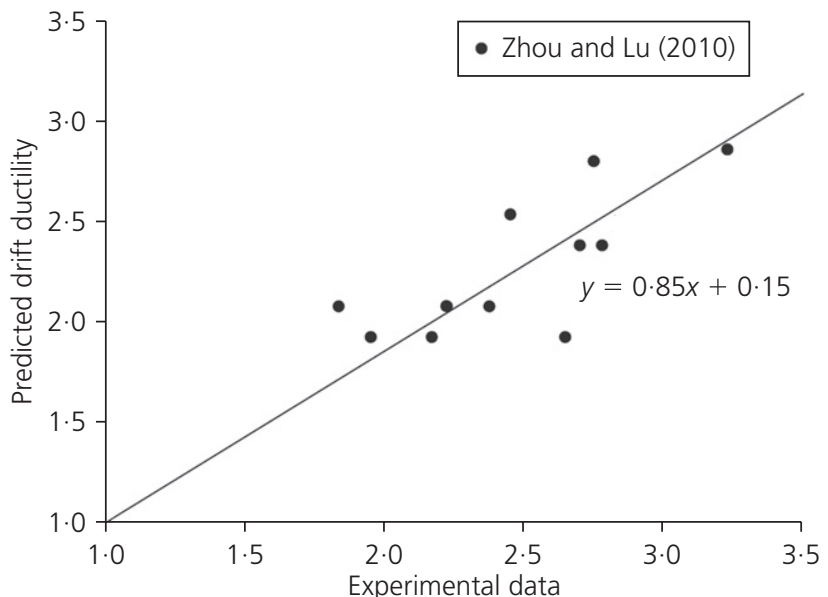

(a)

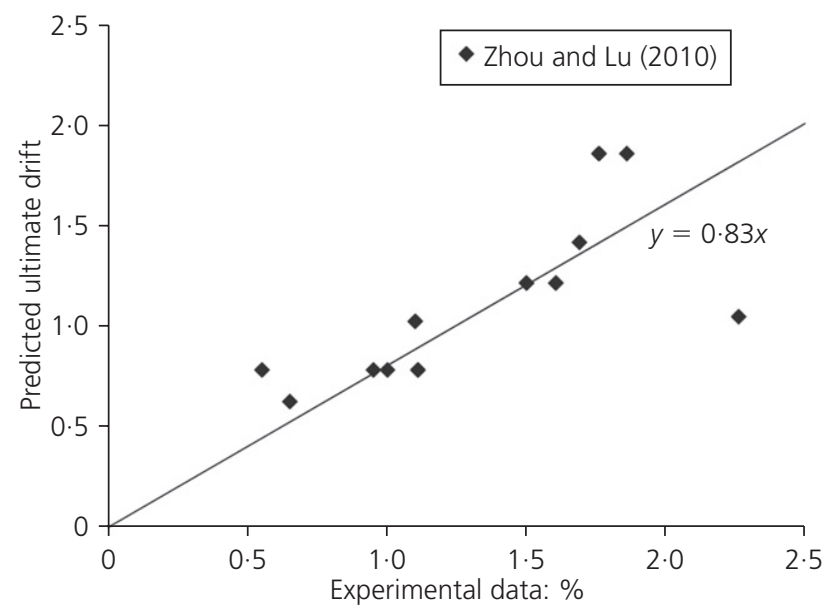

(b)

Figure 4. Predicted drift ductility and ultimate drift ratio plotted against experimental data (Zhou and Lu, 2010)

7. $\varepsilon_{\mathrm{cu}}=0.004+1.4 \omega_{\mathrm{v}} \varepsilon_{\mathrm{sm}} f_{\mathrm{c}} / f_{\mathrm{cc}}$

where $f_{1}$ is the effective confining stress provided by the confining reinforcement. By assuming the walls fail in the flexural mode and the concrete confinement effectiveness is 0.7 for the boundary elements, the influence of the ACR on the displacement capacity and ductility can be evaluated, as shown in Figures 5 and 6 , respectively. The handy calculation shown above clearly demonstrates the indispensable need for an ACR limit, in view of the diminishing effectiveness of confinement on enhancing the displacement capacity at high values of the ACR. It can be seen from Figures 5 and 6 that there is a quite drastic drop in the displacement capacities, which follows the increase in the ACR from $10 \%$ to $30 \%$, after which the relationship curves stagnate and tend to converge to the same value of ductility or ultimate displacement, and thus the confinement details become irrelevant thereafter. Meanwhile, it is interesting to note that high aspect ratios have a negative effect 

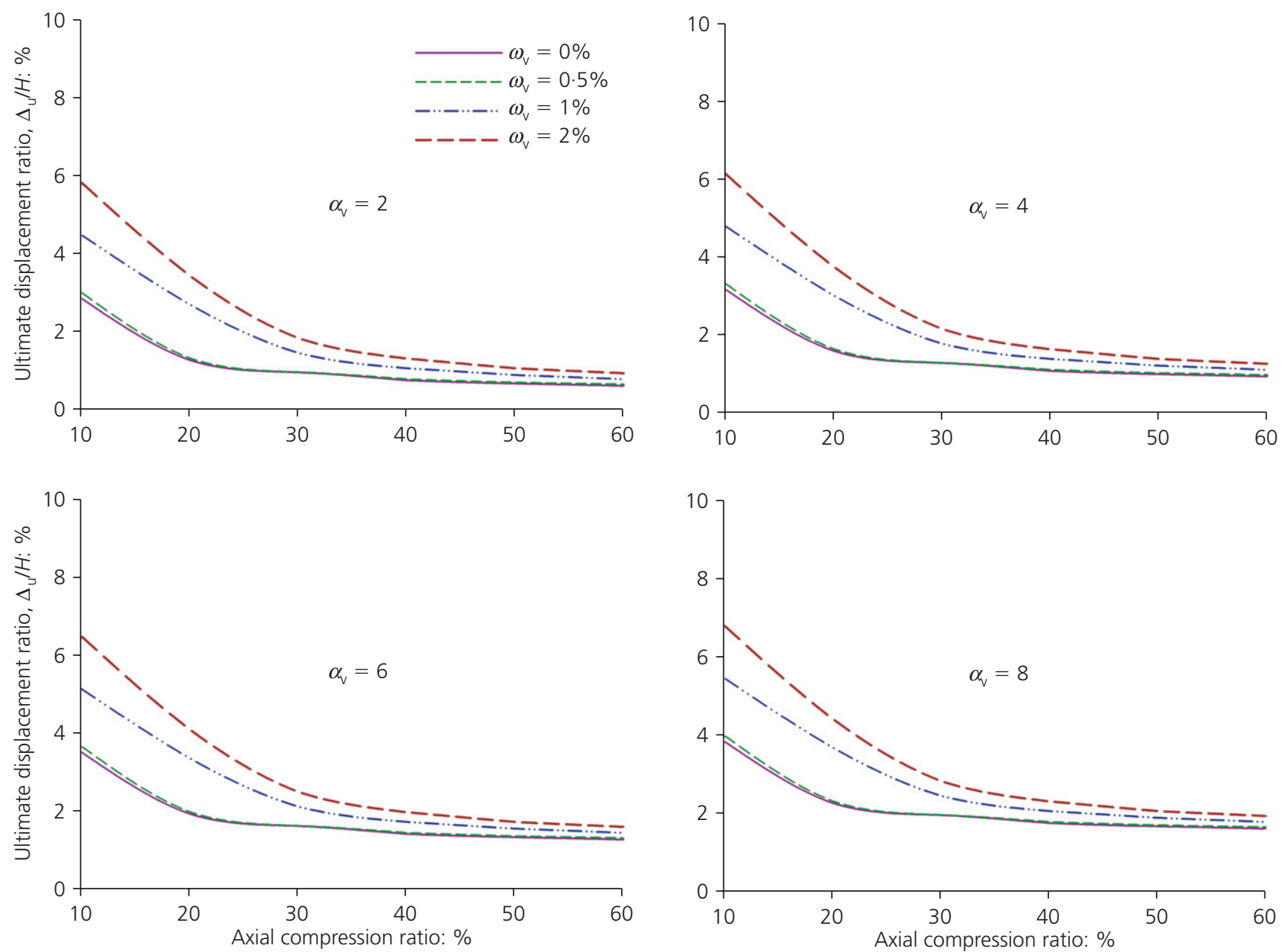

Figure 5. Effect of the ACR on the ultimate displacement ductility of RC walls

on the ductility but are beneficial to the ultimate displacement, although the latter is less sensitive to the value of the aspect ratio than is the ductility. However, the real relationship between the ACR and the displacement capacity is far more complicated, as will be seen later, owing to the fact that each influencing factor can interact with the others, resulting in complex overall structural behaviour (e.g. various factors, including the axial force, aspect ratio, stiffness and cracks, can come into play in the elasto-plastic buckling of walls). Furthermore, it should be noted that the above calculation is based on the assumption of flexural control, which may not be valid for squat walls with an aspect ratio lower than 1.5. Wallace and Elwood (2006) cover the evaluation of the seismic capacity of squat walls.

\subsection{Statistical analysis}

Besides the confinement detailing, aspect ratio and axial compression, the ductility and general seismic performance of RC columns can be influenced by various other factors, such as the anchorage, loading pattern etc., the effects of which in turn interact with the confinement and axial load effect. In view of this complicated behaviour, the quantification of the effect of axial compression on the seismic performance of RC walls has relied heavily on experimental data. Therefore, a comprehensive statistical study was undertaken to evaluate and quantify the effect of the axial force ratio on the seismic performance of RC walls. A non-linear regression analysis was performed using the Levenberg-Marquardt-Fletcher algorithm (Fletcher, 1971). A total of 474 sets of data, comprising experimental results for small to full-scale RC walls of various shapes and detailing methods, were collected from the literature (Adebar et al., 2007; Ali and Wight, 1991; Barda et al., 1977; Birely, 2011; Bohl and Adebar, 2011; Borg et al., 2012; Cardenas and Magura, 1973; Carrillo and Alcocer, 2012a, 2012b; Dazio et al., 2009; Devi et al., 2011; Ghorbani-Renani et al., 2009; Han et al., 2002; Hidalgo et al., 2002; Hirosawa, 1975; Kazaz et al., 2012; Kuang and Ho, 2008; Lefas and Kotsovos, 1990; Lefas et al., 1990; Liao et al., 2009; Morgan et al., 1986; Oesterle, 1986; Pilakoutas and Elnashai, 1995; Qian and Chen, 2005; Qian et al., 2012; Riva and Franchi, 2001; Salonikios et al., 1999; 

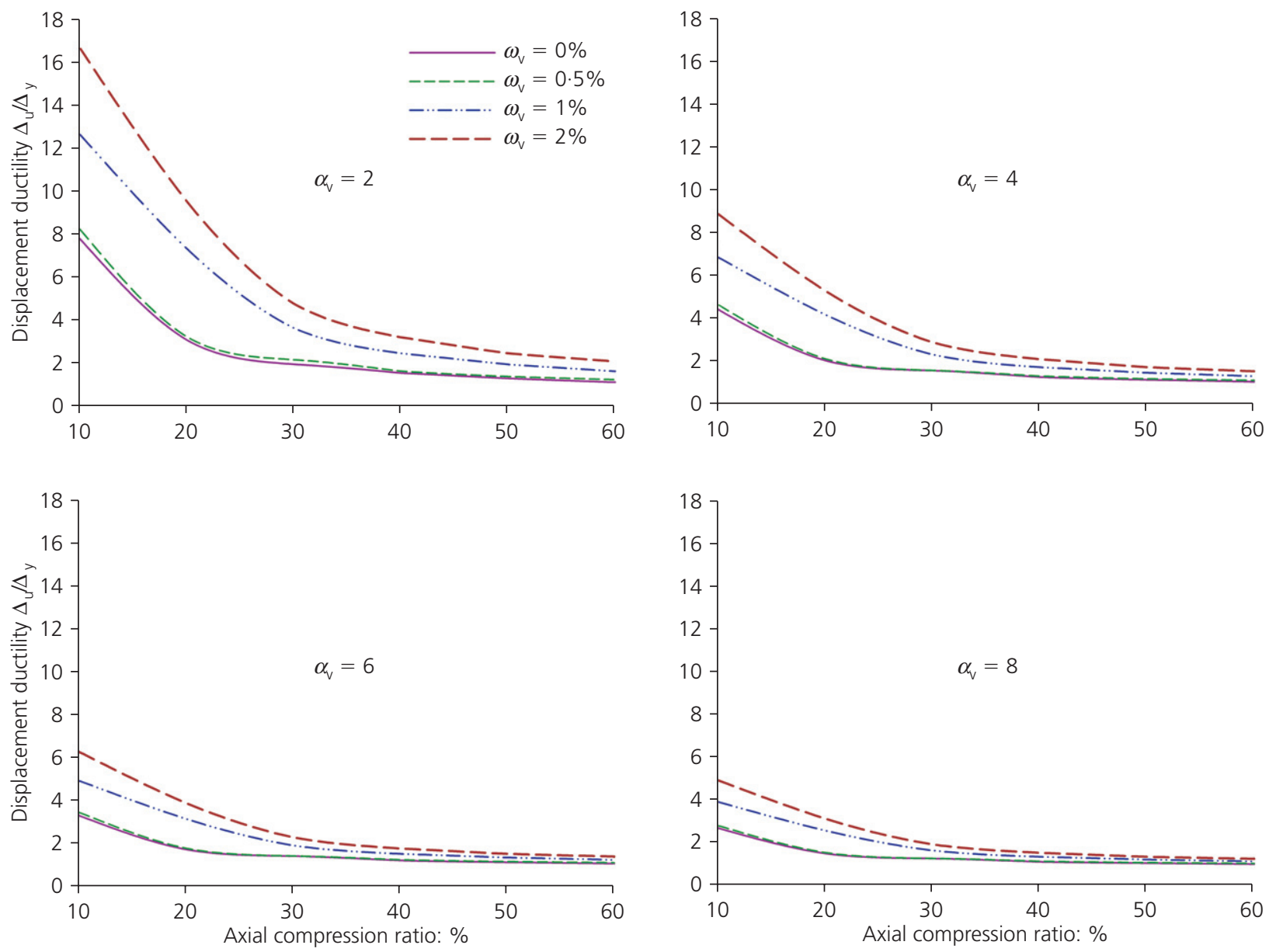

Figure 6. Effect of the ACR on the displacement ductility of $\mathrm{RC}$ walls

Shiu et al., 1981; Su and Wong, 2007; Takahashi et al., 2013; Thomsen and Wallace, 1995; Vallenas et al., 1979; Wallace and Elwood, 2006; Wallace and Moehle, 1991; Wang et al., 1975; Yuen et al., 2004; Zhang and Wang, 2000; Zhou and Lu, 2010). The load-displacement data gathered were then analysed using definitions of yield displacement, ultimate displacement and displacement ductility of the loading curves based on the work by Park (1989). In the collected database, more than $60 \%$ of the tests had been conducted under a relatively low axial force ratio $(<0 \cdot 05)$, while only about $15 \%$ and $7 \%$ were tested with an axial force ratio above $0 \cdot 15$ and $0 \cdot 30$, respectively. Nonetheless, these high axial force tests demonstrated that $\mathrm{RC}$ walls will fail in a very particular manner, such as out-of-plane buckling, resembling the observed modes of damage to walls seen in the 2010 Chile earthquake. RC walls that have failed in outof-plane buckling are generally very brittle and exhibit low ductility, so the classical methods of evaluating ductility, which assuming in-plane flexural failure, are no longer applicable. The relationship between the ultimate displacement capacity and the ACR for various types of RC shear walls having different aspect ratios $H / L$ is plotted in Figure 7(a). The statistical analysis followed the design codes in defining the ACR limit, in that no differentiation was made between different types of walls. Nonetheless, it is recognised that the failure behaviour of different types of wall can be very different even under the same ACR. Hence, the data were disaggregated further into two groups - squat and non-squat walls - for individual statistical analysis. Similar to the analytical results shown in Figure 4, for slender walls there is a trend of diminishing ultimate displacement capacity with increasing ACR (Figure 7(b)), owing to the reduction in the neutral axial depth, the low-cycle fatigue effect as well as potential out-of-plane buckling.

Conversely, the ultimate displacement capacity of squat walls tends to increase with increasing ACR (Figure 7(c)). This reversed trend is actually due to the fact that the shear strength and sliding resistance of cracks in squat walls are enhanced by axial compression. Furthermore, it can be seen that the standard deviation varies with the ACR. Such variation is consistent with the physical and mechanical behaviour of the walls. When the ACR is low, the failure behaviour can be strongly influenced by the reinforcement detailing, resulting in a large 


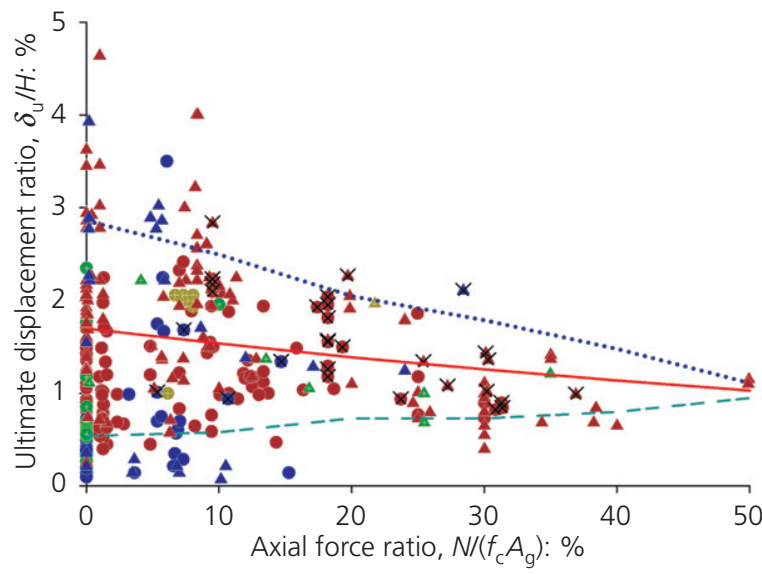

(a)

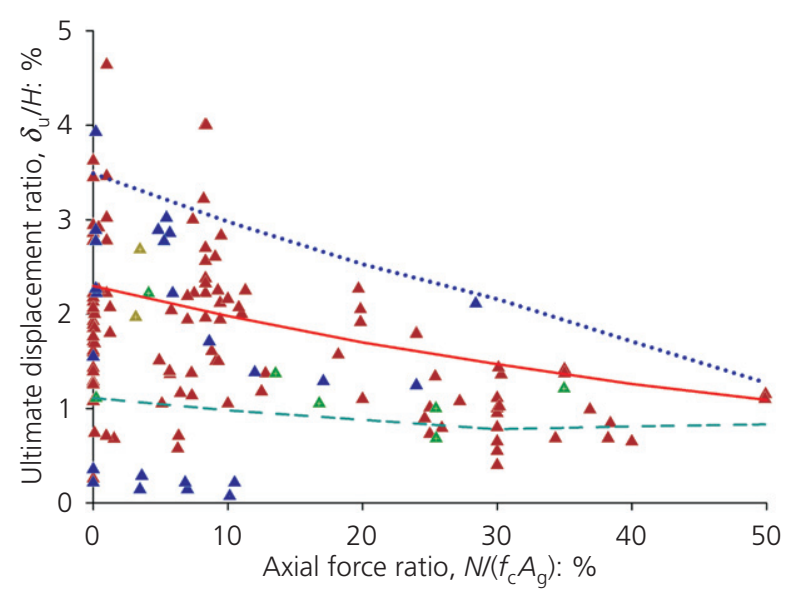

(b)



(c)

Figure 7. Relationship between the ultimate displacement capacity and the ACR: (a) various types of RC wall; (b) non-squat walls $(H / L>1 \cdot 5)$; (c) squat walls $(H / L \leq 1 \cdot 5)$

variation in the data. But when the ACR is high, compression failure or buckling dominate the wall failure, and hence the reinforcement detailing has little influence on the failure behaviour, resulting in little variation in the data.
Figure 8(a) shows the relationship between the drift ductility and the axial force ratio for $\mathrm{RC}$ walls of various kinds. It can be seen that RC walls can easily achieve a high ductility factor $\left(\mu_{\Delta} \geq 6\right)$ at a low axial force ratio $(\eta \leq 10 \%)$ as long as the 
boundary elements are well detailed and designed. However, when the ACR increases to above $20 \%$, the RC walls can only just maintain moderate ductility $\left(4<\mu_{\Delta} \leq 6\right)$, and special detailing methods such as composite-reinforced boundary elements are necessary in order to acquire high ductility. It has been reported that above $35 \%$ ACR the dominant failure mode can be pre-emptive out-of-plane buckling (Su and Wong, 2007; Zhang and Wang, 2000), resulting in the RC walls not being able to

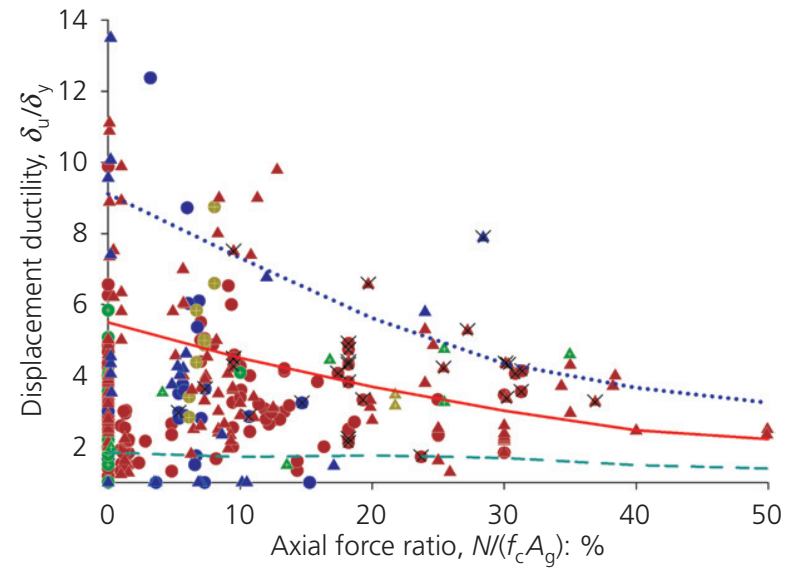

(a)

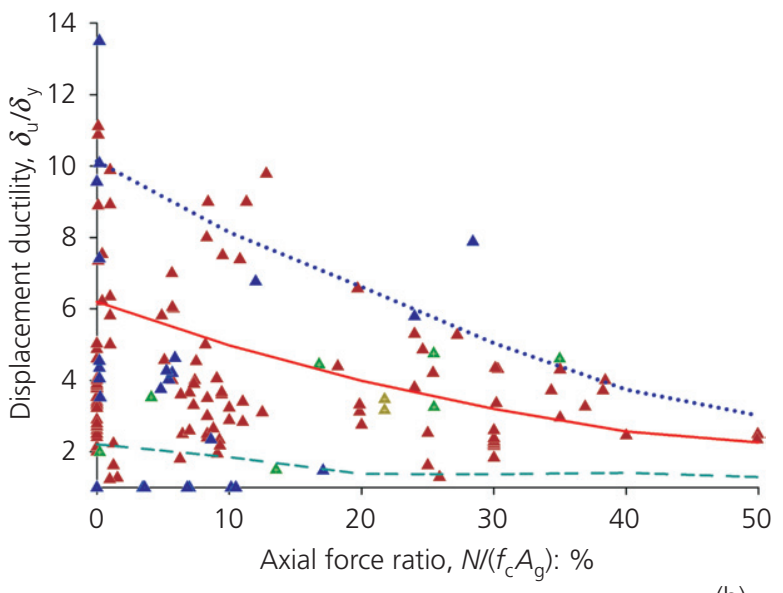

(b)

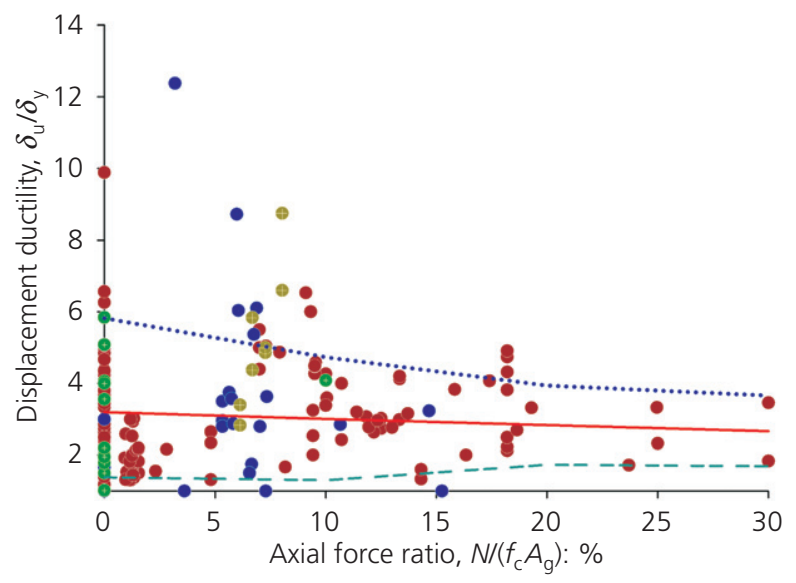

(c)


Figure 8. Relationship between the displacement ductility factor and the ACR: (a) various types of RC wall; (b) non-squat walls $(H / L>1 \cdot 5)$; (c) squat walls $(H / L \leq 1 \cdot 5)$ 
provide lateral and vertical resistance in seismic design. It is recognised that squat $\mathrm{RC}$ walls with aspect ratios $(H / L)$ lower than 1.5 will be prone to shear failure, in particular sliding shear failure (rather than flexural failure), but the displacement ductility is not necessarily reduced by the increase in axial compression. In contrast to non-squat walls (Figure 8(b)), the ductility of squat walls is less influenced by the ACR and the ductility factors generally stay within the range $2<\mu_{\Delta} \leq 4$, as shown in Figure 8(c). For shear-controlled walls, little or no flexural yielding will occur before shear failure (Wallace and Elwood, 2006). On the one hand, high axial compression can suppress the flexural yielding, and hence reduce the ductility of squat walls. On the other hand, axial compression can increase the shear friction on the crack faces in the walls (Wallace and Elwood, 2006), favouring the overall behaviour and ultimate drift capacity of the walls. Hence, the drift ductility - ACR and drift capacity - ACR relationships show different trends, as can be seen in Figures 7(c) and 8(c).

Another important structural property of RC walls related to the axial compression is the shear strength. For comparison purposes, the peak base shears reported for the tests included in the database were further normalised using

8. $\quad v_{\mathrm{n}}=\frac{V_{p}}{f_{\mathrm{c}}^{0.5} A_{\mathrm{w}}}$

where $A_{\mathrm{w}}$ is web area of the wall. Figure 9 shows the relationship between the normalised shear strength and the ACR. Higher axial compression tends to increase the shear strength of all types of RC walls, in particular squat RC walls, as shown in Figure 9(c). This is because axial compression can enhance not only the shear strength of walls but in some cases also the moment resistance (Kappos and Penelis, 1996; Wallace et al., 2012).

\section{Code provisions for the ACR}

In view of the adverse effect of axial compression on the seismic performance of RC structural walls (as illustrated in the last section), most of the modern design codes of practice for RC structures stipulate upper limits of the ACR. RC walls with an ACR beyond the limits are generally deemed to be ineffective in resisting seismic action, even with confinement detailing in the critical regions (expected plastic hinges) of the members. The aim of these provisions, in addition to confinement detailing, is to ensure that sufficient drift ductility and axial force carrying capacity can be retained in RC structures during earthquakes or other exceptional load cases.

\subsection{Eurocode 8 (BS EN 1998-1:2004)}

Eurocode 8 (BSI, 2004) stipulates upper limits of the ACR (normalised axial force) for ductile walls and columns designed for ductility classes 'moderate' and 'high' (DCM and $\mathrm{DCH}$ ), but no restrictions for ductility class 'low' (DCL), as follows

9. $\frac{N_{\mathrm{ED}, \mathrm{EC}}}{f_{\mathrm{cd}} A_{\mathrm{c}}} \leq\left\{\begin{array}{cc}0.35 & \mathrm{DCH} \\ 0.4 & \mathrm{DCM} \\ - & \mathrm{DCL}\end{array}\right.$

(BS EN 1998-1 : 2004)

where $N_{\mathrm{ED}, \mathrm{EC}}$ is the design axial force from the analysis for seismic design equal to

10. $N_{\mathrm{ED}, \mathrm{EC}}=G_{k}+\sum_{i} \psi_{E, i} Q_{k i}+E$

in which $\psi_{E, i}$ is the combination coefficient $(\leq 1)$ for variable action $Q_{k i}$ and $E$ is the seismic action; and $f_{\text {cd }}$ is the design cylinder strength (factored with a safety factor of 1.5 ) of concrete under uniaxial compression at 28 days, $A_{\mathrm{c}}$ is the gross area of the concrete section and $G_{\mathrm{k}}$ is the total permanent or dead load. The design axial force calculated using Equation 9 consists of two major parts: the axial force induced by representative gravity action, and the axial force induced by seismic action. It also includes the effect of seismic actions on RC walls.

Although axial forces incurred in cantilever walls by seismic actions are relatively minor as compared with permanent gravity action in general, coupled shear walls would have to bear significant extra axial forces incurred by seismic actions, due to the coupling action aggregated from the shear forces of the coupling beams, which obviously has a nonnegligible effect on the seismic performance of the walls. Therefore, the definition of the ACR in Eurocode 8 can be considered the most appropriate description of realistic stress states experienced by RC structures during earthquakes. In fact, the limits of the ACR stipulated in Eurocode 8 can be readily compared with experimental studies to see whether the provisions can ensure sufficient ductility of RC members.

\subsection{Chinese seismic design code 2010 (GB50011-2010)}

In the Chinese seismic design code (MCPRC, 2010), the upper limits of the ACR for RC shear walls (sectional aspect ratio $L / t$ >8) take different values under different design fortification earthquake intensities and structure grades (four classes, I to IV: for grade I structures have high drift ductility, grade II and III structures have moderate to high drift ductility, and grade IV structures have relatively low drift ductility) as follows

11. $\frac{N_{\mathrm{W}, \mathrm{C}}}{f_{\mathrm{c}}^{\prime} A_{\mathrm{c}}} \leq\left\{\begin{array}{cl}0.4 & \text { Grade I, intensity } 9 \\ 0.5 & \text { Grade I, intensity } 7 \text { or } 8 \\ 0.6 & \text { Grade II or III } \\ - & \text { Grade IV }\end{array}\right.$ 


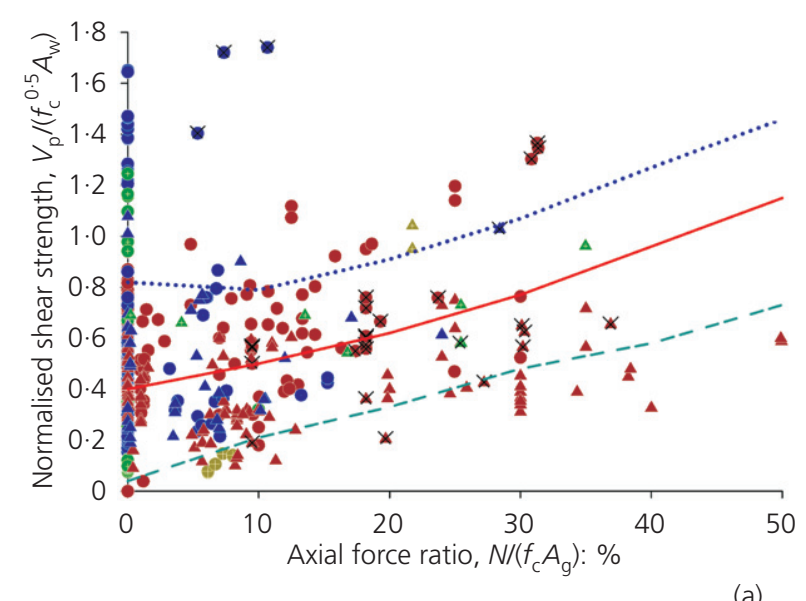

\begin{tabular}{|c|c|}
\hline - & Rectangular $(H / L<1.5)$ \\
\hline & Barbell $(H / L<1.5)$ \\
\hline • & Flanged $(H / L<1.5)$ \\
\hline - & Special $(H / L<1.5)$ \\
\hline$\Delta$ & Rectangular $(H / L>1.5)$ \\
\hline$\Delta$ & Barbell $(H / L>1 \cdot 5)$ \\
\hline$\Delta$ & Flanged $(H / L>1.5)$ \\
\hline$\Delta$ & Special $(H / L>1 \cdot 5)$ \\
\hline$\times$ & Composite boundary elements \\
\hline
\end{tabular}

(a)
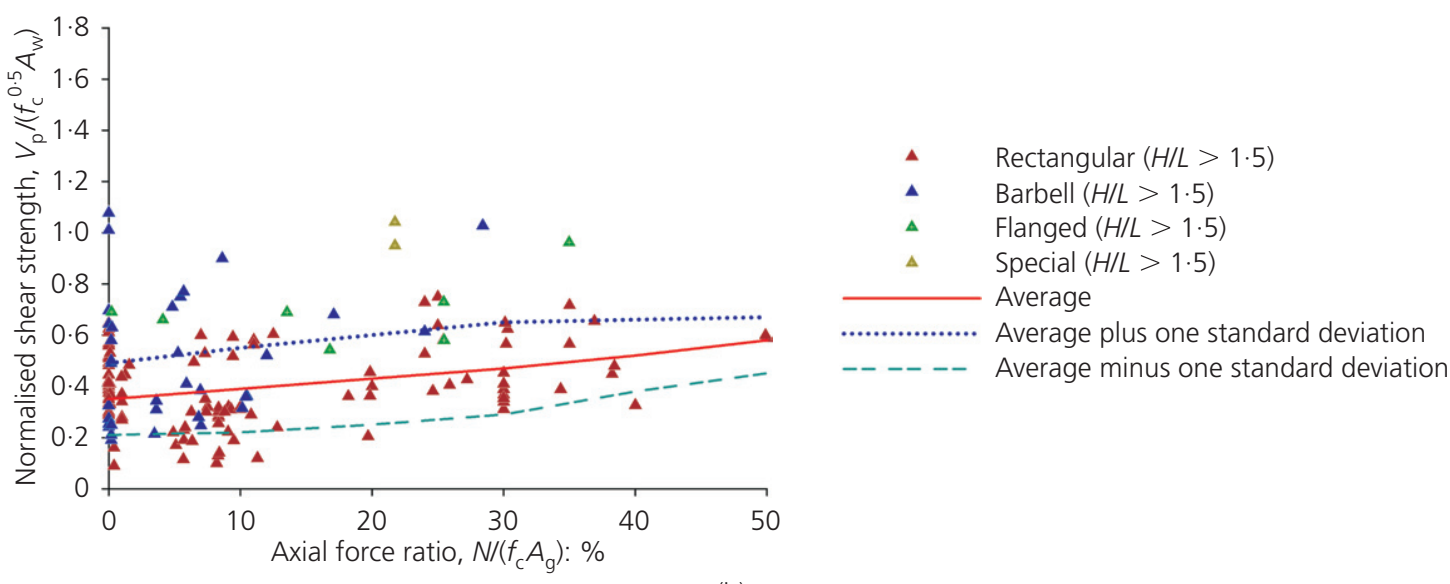

(b)
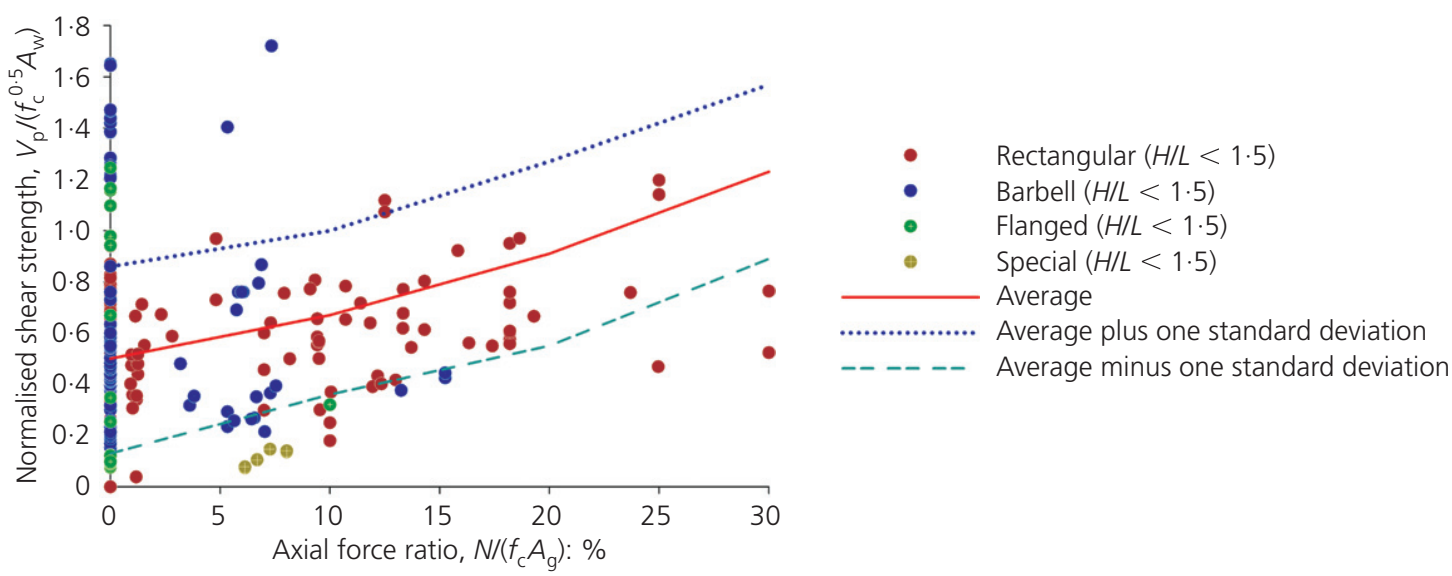
where $N_{\mathrm{W}, \mathrm{C}}$ is the factored axial force for the wall equal to

$$
\text { 12. } N_{\mathrm{W}, \mathrm{C}}=1 \cdot 2\left(G_{\mathrm{k}}+\sum_{i} r_{\mathrm{d} i} Q_{\mathrm{k} i}\right)
$$

in which $r_{\mathrm{d} i}$ is the combination coefficient $(\leq 1)$ for variable action $i$ due to the representative gravity load, and $f_{\mathrm{c}}^{\prime}$ is the design axial compressive strength of concrete under uniaxial compression at 28 days (equal to the characteristic axial strength of concrete $f_{\mathrm{ck}}^{\prime}$ divided by the safety factor 1.4).

The characteristic axial strength $f_{\mathrm{ck}}^{\prime}$ is determined in a $150 \times 150 \times 300 \mathrm{~mm}$ prism compression test, which in this code can be conservatively taken as 0.67 of the characteristic cube strength $f_{\mathrm{cu}, \mathrm{k}}$. The average value of the ratio $f_{\mathrm{ck}}^{\prime} / f_{\mathrm{cu}, \mathrm{k}}$, the socalled 'effectiveness factor', is around $0 \cdot 76$, based on experimental studies (Nielsen, 1999; Zhang, 1993). More stringent provisions are set for short-pier RC shear walls $(4<L / t \leq 8)$, such that the values of the ACR for grades I, II and III shortpier walls should not exceed $0.45,0.50$ and 0.55 , respectively, in the critical regions (MCPRC, 2012). The axial force in Equation 11 is calculated using the representative gravity action, rather than the ultimate gravity action, which the structure is expected to take during earthquakes, and the multiplying factor of 1.2 is used to account for additional axial force incurred by unforeseen and excluded actions on the walls. In the calculation of the representative gravity action, the combination coefficient $r_{\mathrm{di}}$ is used to consider the reduced likelihood that full variable actions are present during earthquakes; for instance, $r_{\mathrm{di}}$ for a residential floor live load is 0.5 .

\subsection{Hong Kong concrete code 2013}

In the Hong Kong concrete code (HKSAR-BD, 2013), the upper limit of the ACR for RC structural walls is specified as follows

13. $\frac{N_{\mathrm{W}, \mathrm{HK}}}{0.45 f_{\mathrm{cu}} A_{\mathrm{c}}} \leq 0.75$

where $N_{\mathrm{W}, \mathrm{HK}}$ is the design axial force equal to

14. $N_{\mathrm{W}, \mathrm{HK}}=1.4 G_{\mathrm{k}}+1.6 Q_{\mathrm{k}}$

in which $G_{\mathrm{k}}$ is the total permanent or dead load and $Q_{\mathrm{k}}$ is the total live load, for the wall due to gravity load; $f_{\text {cu }}$ is the characteristic cube strength of concrete under uniaxial compression at 28 days, and $A_{\mathrm{c}}$ is the gross area of the concrete section. Note that the safety factor for the concrete compressive strength used in the HK code is 1.5 , and dividing the characteristic concrete strength by this factor gives the design strength. The constant $0.45=0.67 / 1.5$ in the denominator converts the characteristic concrete strength into the equivalent design compressive strength for the sections subjected to dominant flexural bending action, wherefore another multiplying factor 0.67 is used. Meanwhile, the axial force in the numerator takes the ultimate load value due to sole gravity action, without consideration of possible non-permanent live load reduction or representative gravity action during rare events with exceptional loading actions such as earthquakes.

\subsection{New Zealand and other design codes}

The New Zealand concrete code (SNZ, 2006) does not have similar provisions regarding the axial force ratios as in the European, Chinese and Hong Kong codes, but limiting sectional curvatures or strains in potential plastic hinge regions are specified for different RC members (clause 2.6.1.3.4, NZS 3101.1\&2:2006). Limiting material strains is apparently the most direct method to control curvature dualities of $\mathrm{RC}$ members; however, whether it is sufficient to prevent the lowcycle fatigue phenomenon or rapid strength and stiffness degradation of RC members under cyclic loading is uncertain.

It is also worth mentioning here that the US concrete design code ACI 318-11:2011 (ACI, 2011) also does not introduce similar limits on the ACR for RC columns and walls. Nevertheless, a US standard for the seismic rehabilitation of buildings, ASCE/SEI 41-06:2007 (ASCE, 2007; Park, 1989), states that RC walls with axial loads greater than $35 \%$ of the nominal axial load strength $P_{0}$ shall not be considered effective in resisting seismic forces. The Canadian concrete code, CSA A23.3-04 (CSA, 2010), also states that flexural members with factored axial loads in excess of $0.35 P_{0}$ shall have a nominal resistance greater than the induced member force, (i.e. not to be designed to form potential plastic hinges and dissipate energy in any circumstances under seismic effects).

\subsection{Comparison of code provisions}

Although the definitions of the axial force ratios in the European, Chinese and Hong Kong codes are somewhat dissimilar, particularly with regard to the axial forces in the numerators, the compressive strength terms in the denominators can be readily transformed to give a characteristic cylindrical strength $f_{\mathrm{c}}=0.8 f_{\mathrm{cu}}=f_{\mathrm{cd}} / 1.5$ for comparison purposes. Table 1 summarises the key comparisons of the provisions on the ACR defined in the three codes.

The ACR limits stipulated in the Chinese code resemble those in Eurocode 8 but, as mentioned before, the combinations of actions for calculating the axial forces are different in the two codes. For cantilever walls, the Chinese code is more stringent because a safety factor of $1 \cdot 2$ is used to amplify the action. However, for coupled shear walls, it is not conclusive which of the two codes is more conservative, as the factor of 1.2 may not be sufficient to cover the exceeding axial forces induced by the coupling action.

Nevertheless, Eurocode 8 provides a more realistic assessment for these cases by taking into consideration seismic or generally lateral force effects. At first sight, looking at the last row 


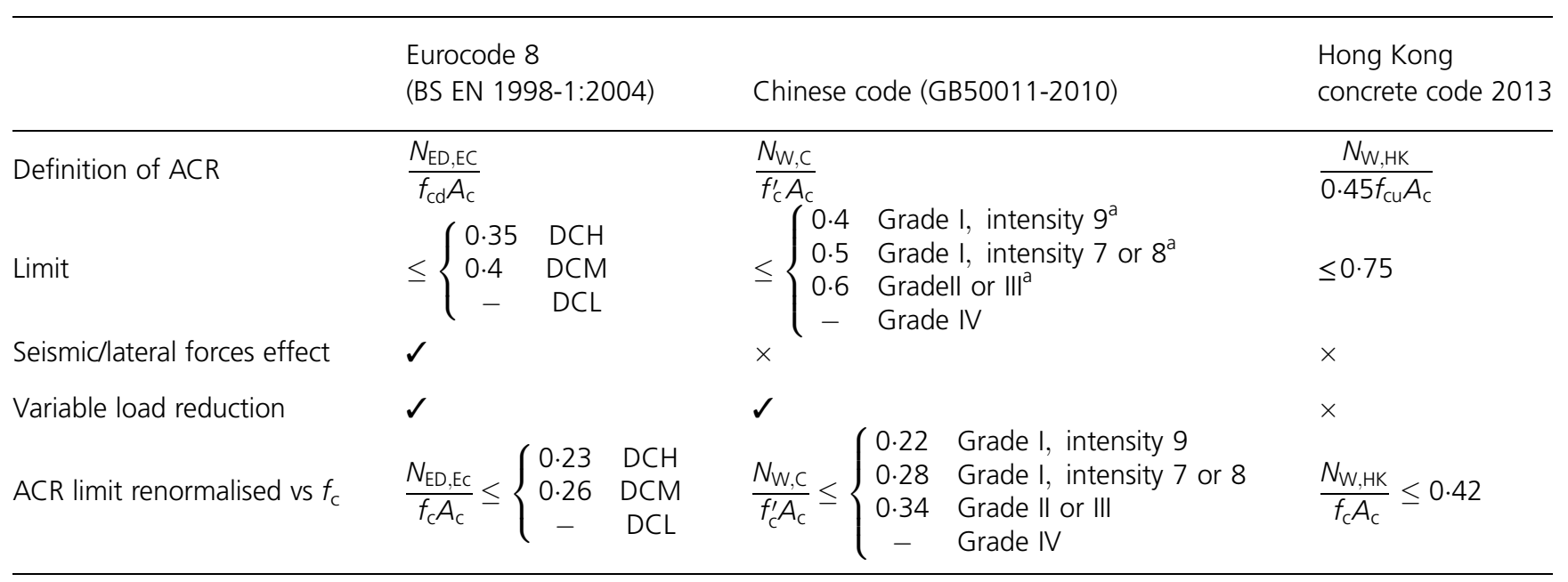

${ }^{a}$ Limits for grades I, II and III short-pier RC shear walls $(4<H / B \leq 8)$ are $0.45,0.50$ and 0.55 , respectively

Table 1. Comparison of code provisions for the ACR of RC walls

in Table 1, the Hong Kong code has the least stringent limit on the ACR for RC walls compared with the other two codes. But it should be noted that the axial force in the numerator is generally much larger, given that full ultimate gravity action is considered instead of representative gravity action. The relationship between the displacement ductility factor and ACR shown in Figure 7 is re-plotted with the code-specified limits on the ACR in Figure 10(a), where the expected achievable ductility of RC walls can be clearly seen.

In Eurocode 8, for multi-storey uncoupled RC-walled buildings with a fundamental period $T_{1}$ longer than the period $T_{\mathrm{c}}$ at the upper limit of the constant acceleration region of the responses spectrum, the displacement ductility factor $\mu_{\delta}$ is equal to the behaviour factor $q$ (BSI, 2004), the basic values of which are 3.0 and 4.8 for DCM and DCH, respectively. Eurocode 8 provisions undoubtedly satisfy this target level of ductility, provided that the boundary elements are properly detailed. The grade I structures designed to the Chinese code can also satisfy this target but the grade II or III structures may have only restricted inherent ductility and are susceptible to out-of-plane buckling. However, the Hong Kong code limit is somewhat unjustifiable in the sense that the target is to control the ductility.

It is noted that walls having different reinforcement detailing would attain different ductility, even if they were subject to the same ACR. However, under high values of the ACR the use of reinforcement detailing is no longer effective in enhancing the ductility, as the failure mode changes from flexural to compression or buckling. In this sense, reinforcement detailing plays a minor role in defining the ACR limit, which is used to control the failure mode of walls.
Nevertheless, the wall configuration and aspect ratio do play an important role in controlling the behaviour of walls even under high values of the ACR. The data in Figure 10(a) can be split into data for non-squat $(H / L>1 \cdot 5)$ and squat $(H / L \leq$ 1.5) walls, as done previously, and the resultant plots are shown in Figure 10(b) and 10(c). For non-squat walls, it can be seen that there is still room for the ACR limits stipulated in Eurocode 8 to be relaxed, for instance to $0 \cdot 25$ and $0 \cdot 3$ for DCH and DCM, respectively, whereas for squat walls the ACR has apparently little effect on wall ductility. However, as shown in Figure 7(c), the axial force tends to increase the ultimate displacement of squat RC walls, which is clearly beneficial in the state-of-the-art displacement-based design methods (Priestley et al., 2007). It may be concluded that squat walls are not suitable to be designed to allow inelastic deformation or as an energy-dissipating element.

\section{Conclusion}

In the design of medium and high-rise buildings, RC shear walls are often used to provide excellent lateral stability and ductility to the structures under the action of wind or earthquakes. In general, shear walls are subjected to very high axial compression, which has been pushing the limits of conventional design and analysis theories.

A comprehensive statistical analysis of 474 sets of experimental data was conducted to investigate the effect of the ACR on the structural performance of various types of RC walls. It was shown that the ductility of the walls reduces generally with increasing ACR. This trend is particularly noticeable for nonsquat walls having an aspect ratio $H / L>1 \cdot 5$. Provisions on the limits of the ACR stipulated in various design codes of practice were compared, and the expected attainable ductility of $\mathrm{RC}$ 


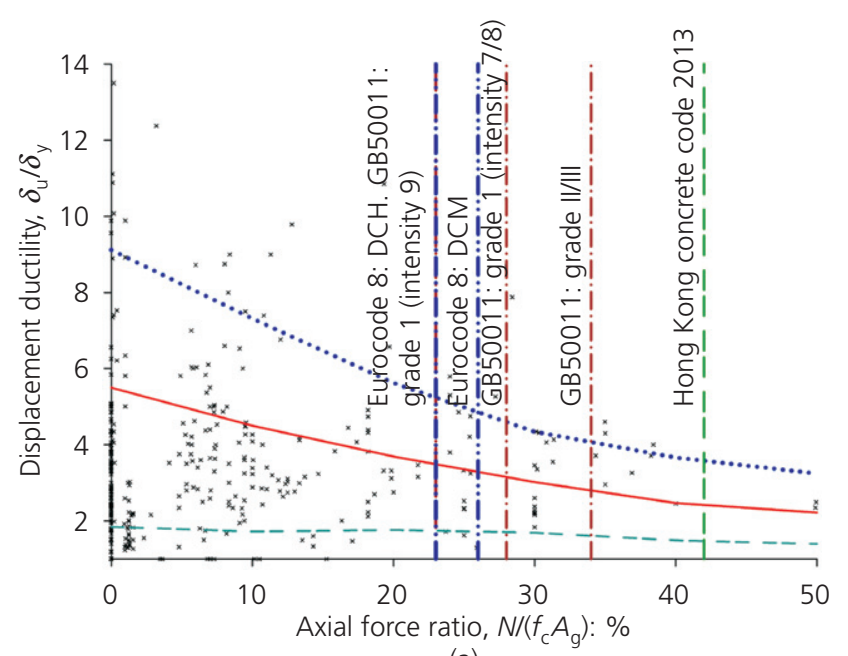

(a)

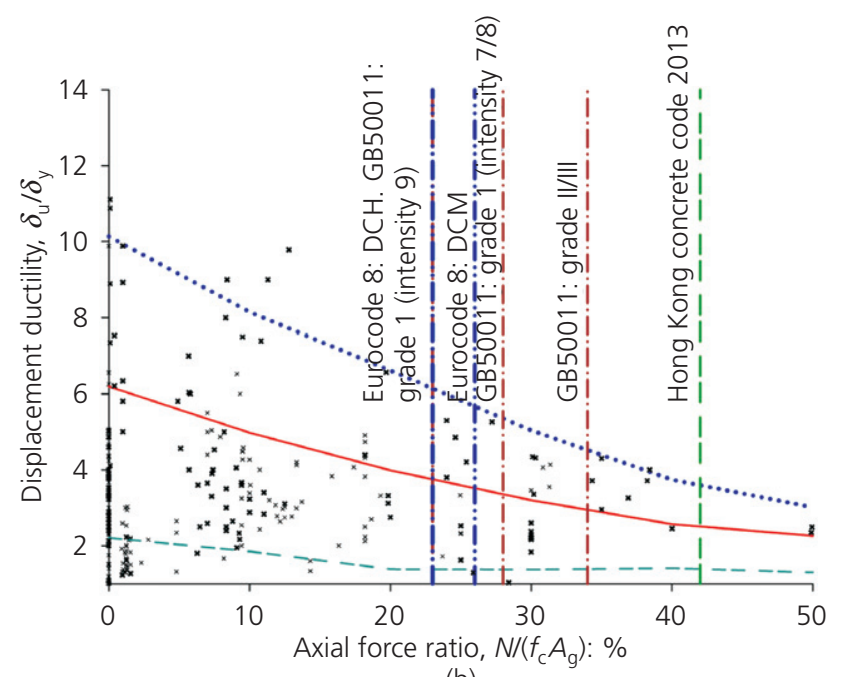

(b)



(c)

Figure 10. Relationship between code-specified ACR limits and the expected displacement ductility: (a) various types of RC wall; (b) non-squat walls (H/L>1.5); (c) squat walls $(H / L \leq 1 \cdot 5)$ walls designed to different codes was evaluated against the results of the statistical analysis.

Based on the results of the analysis, it was found that Eurocode 8 provisions on the ACR limits for RC structural walls generally satisfy the target level for ductility. However, the ACR limits may take different values for non-squat and squat walls due to their distinct structural behaviours. It was found in this study that the ACR limits for non-squat walls can be relaxed. However, there is obviously a need to conduct more experimental studies on squat walls under high axial compression loading before definite conclusions can be drawn.

\section{Acknowledgements}

The support of the Hong Kong Research Grand Council (HK-RGC) under grant number 614011 and the Scientific and Technological Research Council of Turkey (TÜBİTAK) under project number $214 \mathrm{M} 236$ is gratefully acknowledged.

\section{REFERENCES}

Adebar P (2013) Compression failure of thin concrete walls during 2010 Chile earthquake: lessons for Canadian design practice. Canadian Journal of Civil Engineering 40(8): 711-721.

Adebar P, Ibrahim AMM and Bryson M (2007) Test of high-rise core wall: effective stiffness for seismic analysis. $A C I$ Structural Journal 104(5): 549-559.

Ali A and Wight JK (1991) RC structural walls with staggered door openings. Journal of Structural Engineering 117(5): 1514-1531.

ACI (American Concrete Institute) (2011) ACI 318-11:2011: Building code requirements for structural concrete and commentary. ACI, Farmington Hills, MI, USA.

ASCE (American Society of Civil Engineers) (2007) ASCE/SEI 41-06:2007: Seismic rehabilitation of existing buildings. ASCE, Reston, VA, USA.

Barda F, Hanson J and Corley W (1977) Shear strength of lowrise walls with boundary elements. In Reinforced Concrete Structures in Seismic Zones. American Concrete Institute, Farmington Hills, MI, USA, SP 53-8, pp. 149-201.

Birely AC (2011) Seismic Performance of Slender Reinforced Concrete Structural Walls. PhD thesis, University of Washington, Seattle, WA, USA.

Bohl A and Adebar P (2011) Plastic hinge lengths in high-rise concrete shear walls. ACI Structural Journal 108(S15): 148-157.

Borg RC, Rossetto T and Varum H (2012) The effect of the number of response cycles on the behaviour of reinforced concrete elements subject to cyclic loading. The 15th World Conference on Earthquake Engineering, Lisbon, Portugal.

BSI (2004) BS EN 1998-1:2004: Eurocode 8: Design of structures for earthquake resistance. Part 1: General rules, seismic actions and rules for buildings. BSI, London, UK. 
Cardenas AE and Magura DD (1973) Strength of high-rise shear walls - rectangular cross sections.In Response of Multistory Concrete Structures to Lateral Forces. American Concrete Institute, Farmington Hills, MI, USA, SP-36, pp. 119-150.

Carrillo J and Alcocer SM (2012a) Acceptance limits for performance-based seismic design of RC walls for low-rise housing. Earthquake Engineering \& Structural Dynamics 41 (15): 2273-2288.

Carrillo J and Alcocer SM (2012b) Backbone model for performance-based seismic design of RC walls for low-rise housing. Earthquake Spectra 28(3): 943-964.

Chronopoulos MP and Vinzileou E (1995) Confinement of RC columns. In European Seismic Design Practice (Elnashai AS (ed.)). Balkema, Rotterdam, the Netherlands pp. 341-348.

CSA (Canadian Standard Association) (2010) CSA:A23.3-04 (R2010): Design of concrete structures. CSA, Ontario, Canada.

Dazio A, Beyer K and Bachmann H (2009) Quasi-static cyclic tests and plastic hinge analysis of RC structural walls. Engineering Structures 31(7): 1556-1571.

Devi GN, Subramanian K and Santakumar AR (2011) Experimental investigations on reinforced concrete lateral load resisting systems under lateral loads. Experimental Techniques 35(4): 59-73.

EERI (Earthquake Engineering Research Institute) (2010) Learning from Earthquakes. The Mw $8 \cdot 8$ Chile Earthquake of February 27, 2010. EERI, Oakland, CA, USA, Special Earthquake Report.

fib (Fédération Internationale Du Béton) (2012) Model Code 2010 Bulletin 66. fib, Lausanne, Switzerland, vol. 2.

Fintel M (1992) Need for shear walls in concrete buildings for seismic resistance: observations on the performance of buildings with shear walls in earthquakes of the last thirty years. In Concrete Shear in Earthquake (Hsu TTC and Mau ST (eds)). Elsevier, London, UK, pp. 3442.

Fletcher R (1971) A Modified Marquardt Subroutine for Nonlinear Least Squares. United Kingdom Atomic Energy Authority, Harwell, UK, Report AERE-R 6799.

Ghorbani-Renani I, Velev N, Tremblay R et al. (2009) Modeling and testing influence of scaling effects on inelastic response of shear walls. ACI Structural Journal 106(3): 358-367.

Han SW, Oh YH and Lee LH (2002) Seismic behaviour of structural walls with specific details. Magazine of Concrete Research 54(5): 333-345.

Hidalgo PA, Ledezma CA and Jordan RM (2002) Seismic behavior of squat reinforced concrete shear walls. Earthquake Spectra 18(2): 287-308.

Hirosawa M (1975) Past Experimental Results on Reinforced Concrete Shear Walls and Analysis on Them. Building Research Institute, Ministry of Construction, Tokyo, Japan, Kenchiku Kenkyu Shiryo No. 6 (in Japanese).

HKSAR-BD (Government of the Hong Kong Special Administrative Region - Buildings Department) (2013)
Code of Practice for Structural Use of Concrete 2013. HKSAR-BD, Hong Kong.

Kappos A and Penelis GG (1996) Earthquake Resistant Concrete Structures. CRC Press, Boca Raton, FL, USA.

Kazaz I, Gülkan P and Yakut A (2012) Deformation limits for structural walls with confined boundaries. Earthquake Spectra 28(3): 1019-1046.

Kuang JS and Ho YB (2008) Seismic behavior and ductility of squat reinforced concrete shear walls with nonseismic detailing. ACI Structural Journal 105(2): 225-231.

Lefas ID and Kotsovos MD (1990) Strength and deformation characteristics of reinforced concrete walls under load reversals. ACI Structural Journal 87(6): 716-726.

Lefas ID, Kotsovos MD and Ambrasseys NN (1990) Behaviour of $\mathrm{RC}$ structural walls: strength, deformation characteristics and failure mechanism. ACI Structural Journal 87(1): 23-31.

Liao FY, Han LH and Tao Z (2009) Seismic behaviour of circular CFST columns and RC shear wall mixed structures: experiments. Journal of Constructional Steel Research 65(8-9): 1582-1596.

Mander JB, Priestley MJN and Park P (1988) Theoretical stress-strain model for confined concrete. Journal of Structural Engineering 114(8): 1804-1826.

Morgan BJ, Hiraishi H and Corley WG (1986) US-Japan Quasi Static Test of Isolated Wall Planar Reinforced Concrete Structure. PCA Report. Construction Technology Division, Skokie, IL, USA.

Nielsen MP (1999) Limit Analysis and Concrete Plasticity, 2nd edn. CRC Press, Boca Raton, FL, USA.

MCPRC (Ministry of Construction of the People's Republic of China) (2010) National Standard of People's Republic of China: Code for seismic design of buildings. China Architecture \& Building Press, Beijing, China, GB 50011-2010.

Oesterle RG (1986) Inelastic Analysis for In-plane Strength of Reinforced Concrete Shear Walls. PhD dissertation, Northwestern University, Evanston, IL, USA.

Park R (1986) Ductile design approach for reinforced concrete frames. Earthquake Spectra 2(3): 565-679.

Park R (1989) Evaluation of ductility of structures and structural assemblages from laboratory testing. Bulletin of the New Zealand Society for Earthquake Engineering 22(3): 155-166.

Park R and Paulay T (1975) Reinforced Concrete Structures. Wiley, New York, NY, USA.

Paulay T and Priestley MJN (1992) Seismic Design of Reinforced Concrete and Masonry Buildings. Wiley, New York, NY, USA.

Pilakoutas K and Elnashai AS (1995) Cyclic behaviour of RC cantilever walls. Part I: experimental results. ACI Structural Journal 92(3): 271-281.

Priestley MJN, Calvi GM and Kowalsky MJ (2007) Displacement-Based Seismic Design of Structures. IUSS Press, Pavia, Italy. 
Qian J and Chen Q (2005) A macro model of shear walls for push-over analysis. Proceedings of the ICE - Structures and Buildings 158(2): 119-132.

Qian J, Jiang Z and Ji X (2012) Behavior of steel tube-reinforced concrete composite walls subjected to high axial force and cyclic loading. Engineering Structures 36(3): 173-184.

Riva P and Franchi A (2001) Behavior of reinforced concrete walls with welded wire mesh subjected to cyclic loading. ACI Structural Journal 98(3): 324-334.

Salonikios T, Kappos A, Tegos I and Penelis G (1999) Cyclic load behavior of low-slenderness reinforced concrete walls: design basis and test results. ACI Structural Journal 96(4): 649-660.

Shiu KN, Daniel JI, Aristizabal JD, Fiorato AE and Corley WG (1981) Earthquake Resistant Structural Walls - Tests of Walls With and Without Openings. Portland Cement Association, Skokie, IL, USA.

SNZ (Standards New Zealand) (2006) NZS 3101.1\&2:2006: Concrete structures standard. NZS, Wellington, New Zealand.

Su RKL and Wong SM (2006) A survey on axial load ratios of medium-rise residential buildings in Hong Kong. HKIE Transactions 14(3): 40-46.

Su RKL and Wong SM (2007) Seismic behaviour of slender reinforced concrete shear walls under high axial load ratio. Engineering Structures 29(8): 1957-1965.

Takahashi S, Yoshida K and Ichinose T (2013) Flexural drift capacity of reinforced concrete wall with limited confinement. ACI Structural Journal 110(Suppl 10): 95-104.

Tassios TP (1996) Advances in earthquake-resistant design concrete structures. 11th World Conference on Earthquake Engineering, Acapulco, Mexico, paper No. 2171.

Thomsen JH and Wallace JW (1995) Displacement-Based Design of Reinforced Concrete Structural Walls: An Experimental
Investigation of Walls with Rectangular and T-Shaped Cross-Sections. Department of Civil and Environmental Engineering, Clarkson University, Potsdam, NY, USA, Report No. CU/CEE-95/06.

Vallenas MV, Bertero VV and Popov EP (1979) Hysteretic Behaviour of Reinforced Concrete Structural Walls. Earthquake Engineering Research Center, University of California, Berkeley, CA, USA, UCB/EERC Report $79 / 20$.

Wallace JW and Elwood KJ (2006) An axial load capacity model for shear critical RC wall piers, Proceedings, 8th US National Conference on Earthquake Engineering, San Francisco, CA, USA, Paper 1568.

Wallace JW and Moehle JP (1991) Ductility and detailing requirements of bearing wall buildings. Journal of Structural Engineering 118(6): 1625-1644.

Wallace JW, Massone LM, Bonelli Pet al. (2012) Damage and implications for seismic design of RC structural wall buildings. Earthquake Spectra 28(Suppl 1): 281-S299.

Wang TY, Bertero VV and Popov EP (1975) Hysteretic Behavior of Reinforced Concrete Framed Walls. Earthquake Engineering Research Center, University of California, Berkeley, CA, USA, UCB/EERC Report 75/23.

Yuen H, Choi C and Lee L (2004) Earthquake performance of high-strength concrete structural walls with boundary elements. 13th World Conference on Earthquake Engineering, Vancouver, BC, Canada.

Zhang QX (1993) Concrete Structure Design: Basic Theory, Methods and Examples. Jiangsu Science and Technology Publishing House, Jiangsu, China.

Zhang Y and Wang Z (2000) Seismic behaviour of reinforced concrete shear walls subjected to high axial loading. ACI Structural Journal 97(5): 739-750.

Zhou Y and Lu X (2010) Shear Wall Database from Tongji Univsersity. See https://ntes.org/resources/869 (accessed 11/04/2015). 